\title{
Islet $\beta$ cell expression of constitutively active Akt1/PKB $\alpha$ induces striking hypertrophy, hyperplasia, and hyperinsulinemia
}

\author{
Ernesto Bernal-Mizrachi, Wu Wen, Sarah Stahlhut, Cris M. Welling, and M. Alan Permutt \\ Division of Endocrinology, Diabetes and Metabolism, Washington University School of Medicine, St. Louis, Missouri, USA \\ Address correspondence to: Ernesto Bernal-Mizrachi, Washington University School of Medicine, Division of Endocrinology, \\ Diabetes, and Metabolism, Campus Box 8127, 660 S. Euclid Avenue, St. Louis, Missouri 63110, USA. \\ Phone: (314) 362-7693; Fax: (314) 747-2692; E-mail: ebernal@im.wustl.edu.
}

Received for publication July 17, 2001, and accepted in revised form October 1, 2001.

The phosphoinositide 3-kinase-Akt/PKB pathway mediates the mitogenic effects various nutrients and growth factors in cultured cells. To study its effects in vivo in pancreatic islet $\beta$ cells, we created transgenic mice that expressed a constitutively active Akt1/PKB $\alpha$ linked to an Insulin gene promoter. Transgenic mice exhibited a grossly visible increase in islet mass, largely due to proliferation of insulin-containing $\beta$ cells. Morphometric analysis verified a six-fold increase in $\beta$ cell mass/pancreas, a two-fold increase in 5-bromo-2'-deoxyuridine incorporation, a four-fold increase in the number of $\beta$ cells per pancreas area, and a two-fold increase in cell size in transgenic compared with wildtype mice at 5 weeks. At least part of the increase in $\beta$ cell number may be accounted for by neogenesis, defined by criteria that include $\beta$ cells proliferating from ductular epithelium, and by a six-fold increase in the number of single and doublet $\beta$ cells scattered throughout the exocrine pancreas of the transgenic mice. Glucose tolerance was improved, and fasting as well as fed insulin was greater compared with wild-type mice. Glucose-stimulated insulin secretion was maintained in transgenic mice, which were resistant to streptozotocin-induced diabetes. We conclude that activation of the Akt $1 / \mathrm{PKB} \alpha$ pathway affects islet $\beta$ cell mass by alteration of size and number.

J. Clin. Invest. 108:1631-1638 (2001). DOI:10.1172/JCI200113785.

\section{Introduction}

The normal response of pancreatic islet $\beta$ cells to various conditions associated with insulin resistance is to increase the mass of insulin-producing cells (1). Plasma glucose concentration is an important factor in this response, and prolonged hyperglycemia has been shown to result in increased islet $\beta$ cell mass (2). The exact contributions of cell size (hypertrophy), new $\beta$ cell formation (neogenesis), replication of existing $\beta$ cells, and enhanced survival to the increased islet $\beta$ cell mass following prolonged glucose stimulation in vivo have not been well defined. In general, rates of proliferation and apoptosis are low and difficult to measure in vivo (3). Transgenic mice overexpressing a number of growth factors have also been shown to exhibit increased islet $\beta$ cell mass (4).

Molecular mechanisms involved in proliferation of islet $\beta$ cells have been assessed in isolated rodent islets and in insulinoma cells in culture. Swenne studied the effects of glucose on cell cycle kinetics in isolated islets. He showed that glucose-induced proliferation was associated with an increase in the number of $\beta$ cells entering the cell cycle (5). Both glucose and insulin-like growth factor 1-mediated proliferation of insulinoma cells in culture have been shown to be phosphoinositide 3-kinase (PI3K) dependent (6). A major target of $\mathrm{PI} 3 \mathrm{~K}$ is the serine-threonine kinase Akt, the cellular homologue of the viral oncogene v-Akt (7). Three main highly conserved isoforms of Akt/PKB, expressed by separate genes, have now been identified in mammalian cells (8). Akt was shown to be involved in signal transduction when its kinase activity was found to be enhanced by treatment of cells with growth factors such as PDGF (see ref. 9 for review). In most cases activation is dependent on PI3K. Once activated, Akt in turn phosphorylates a number of downstream targets that in general promote cell growth and survival through regulation of protein synthesis, glycogen metabolism, and cell cycle progression (8).

Because the PI3K-Akt pathway appears likely to be involved in both glucose- and growth factor-mediated regulation of islet $\beta$ cell proliferation $(6,10)$, we hypothesized that creating transgenic mice with increased Akt activity would alter this process. We therefore created mice that expressed a constitutively active Akt linked to an insulin gene promoter. These mice were observed to develop a striking increase in $\beta$ cell mass with resulting hyperinsulinemia. Evidence is presented that this increase in mass is due to enhanced $\beta$ cell hypertrophy as well as hyperplasia.

\section{Methods}

Generation of transgenic mice. The constitutively active Akt1 used for these experiments lacks the $\mathrm{PH}$ domain (Akt $\Delta 4$-129) and contains an N-terminal Src myristolation signal (myrAkt $\Delta 4-129)$ along with an hemag- 


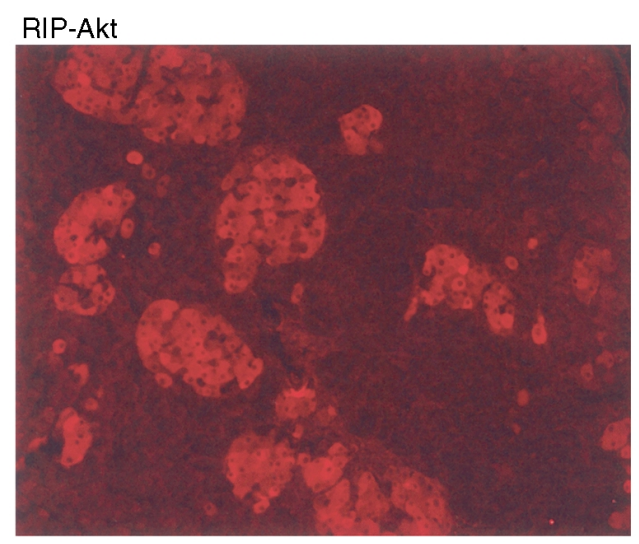

\section{Figure 1}

Transgene expression in RIP-Akt mice. Expression of the transgene was demonstrated by immunofluorescent staining of the pancreas with an anti-HA-tag Ab (red). No signal was observed in pancreas from a control animal (data not shown).

glutinin (HA) tag for monitoring expression (11). This sequence was inserted at the EcoRI site in a RIP-I/ $\beta$-globin expression vector $(12,13)$. This chimeric gene (RIPAkt) was excised by enzymatic digestion, purified, and microinjected into fertilized eggs of C57B16 $\times$ CBA mice according to standard technique (14) by the Washington University Neuroscience Transgenic Facility. Three transgenic founders (no. 167, no. 138, and no. 139) expressing the RIP-Akt chimeric gene with a C57B16 $\times$ CBA genetic background were backcrossed to C57BL6J mice (The Jackson Laboratory, Bar Harbor, Maine, USA), and the $\mathrm{N}_{2}$ generation was analyzed. The studies described herein were performed on animals derived from the number 138 line.

Immunobistochemistry and immunofluorescence. Pancreata were obtained from representative animals as described in Results, fixed overnight in Bouin's solution, and embedded in paraffin using standard techniques. Sections were placed on glass slides, deparaffinized with xylene, and stained with hematoxylin and eosin. Immunostaining for insulin was done by using guinea pig anti-human insulin $\mathrm{AB}$ (1:300; BioGenex Laboratories, San Ramon, California, USA) and the Histomouse-SP kit (Zymed Laboratories Inc., South San Francisco, California, USA) using 3-amino-9-ethyl carbazole (AEC) as chromogen according to the manufacturers' instructions. Endogenous peroxidase was quenched with $0.6 \% \mathrm{H}_{2} \mathrm{O}_{2} /$ methanol for 30 minutes.
For immunofluorescence, primary Ab's were used at the following dilutions: guinea pig anti-human insulin (1:300; BioGenex Laboratories), rabbit anti-glucagon (1:500; Chemicon International, Temecula, California, USA), rabbit anti-somatostatin (1:500; DAKO Corp., Carpinteria, California, USA), rabbit anti-pancreatic polypeptide (1:500; Chemicon International), rabbit anti-HA (1:1000; Santa Cruz Biotechnology Inc., Santa Cruz, California, USA). All primary Ab incubations were performed overnight in a humid chamber. Secondary Ab's were used at the following dilutions: donkey anti-guinea pig FITC (insulin) and donkey antirabbit CY3 (glucagon, somatostatin, pancreatic polypeptide, and HA).

Islet morphometric analysis. Pancreata were obtained from 15-day-old and 5-week-old control and transgenic mice for immunohistochemistry. Detection of insulin was performed in five sections $(5 \mu \mathrm{m})$ separated by 200 $\mu \mathrm{m}$. The islet area (in square micrometers) and the area of each section was determined with the BioQuant image analyzer software package (BQ Classic $98 \mathrm{MR}$; BIOQUANT-R \& M Biometrics Inc., Nashville, Tennessee, USA). The percentage of $\beta$ cell area in the pancreas was calculated by dividing the area of all insulinpositive cells in one section by the total area of this section and multiplying this ratio by 100 . The $\beta$ cell mass was calculated by multiplying the pancreas weight by the percentage of islet area. The data for the 15-day-old mice were calculated only as the percentage of $\beta$ cell area, since the pancreatic weight could not be accurately determined.

Estimation of islet $\beta$ cell proliferation, $\beta$ cell size, and neogenesis. $\beta$ cell replication was determined by 5 -bromo- 2 ' deoxyuridine (BrdU) incorporation. Transgenic and normal littermates were injected intraperitoneally with $120 \mathrm{mg} / \mathrm{kg}$ of BrdU (Cell Proliferation Kit; Amersham Pharmacia Biotech, Piscataway, New Jersey, USA) and sacrificed after 6 hours. Pancreata were fixed and embedded in paraffin as described above and stained with anti-BrdU Ab's (Amersham Pharmacia Biotech) and subsequently with Ab's against insulin. After counterstaining with hematoxylin, the sections were counted in a blinded fashion. Islet cells, which were stained for BrdU and insulin, were considered BrdU-positive $\beta$ cells. At least 1,000 islet $\beta$ cell nuclei were counted per pancreas. The results are expressed as the percentage of BrdU-positive $\beta$ cell nuclei per total number of $\beta$ cell nuclei. The calculation of the number of nuclei per pan-

\section{Figure 2}

Macroscopic abnormalities from transgenic mice expressing a constitutively active Akt $1 / P K B$. Macroscopic findings observed during pancreatic dissections of RIP-Akt (left) and wild-type (WT) (right) mice. Gross identification of islets in pancreas from a transgenic mouse (see arrow for example).

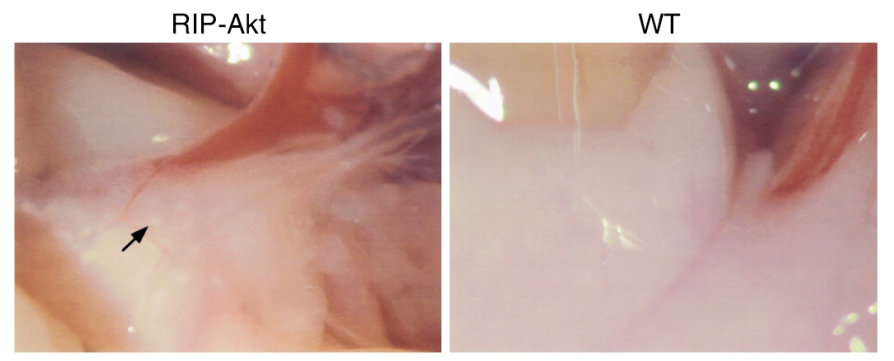




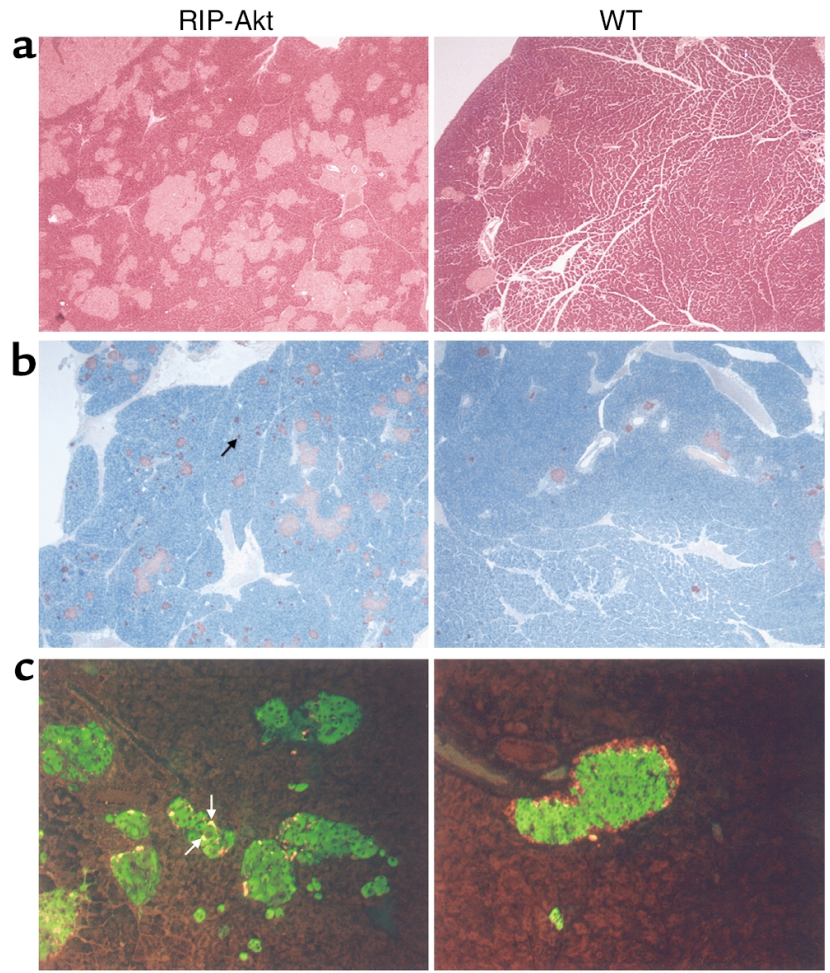

Figure 3

Morphological changes in pancreas from RIP-Akt mice. (a) Hematoxylin and eosin staining of pancreas from a transgenic (left) and control mouse (right), each 24 weeks of age. (b) Immunostaining of pancreas for insulin (red) in 5-week-old transgenic (left) and control mouse (right). Note multiple areas of single and doublet extra-islet $\beta$ cells, indicated by arrow. (c) Altered islet architecture was demonstrated by immunofluorescence staining of pancreas with insulin (green) and non- $\beta$ cells (red) in 5-week-old transgenic (left) and control mouse (right). Occasional cells expressing both insulin and a non- $\beta$ cell hormone are indicated in yellow (see arrows for example).

creatic area was performed in insulin-stained sections. The results are presented as the mean number of nuclei of insulin positive cells divided by the pancreatic area.

To calculate the mean size of the individual $\beta$ cells, the $\beta$ cell area was divided by the number of $\beta$ cell nuclei in the covered area. $\beta$ cell single and doublet measurements were performed in sections from 15 day-old mice stained specifically for insulin. Data are presented as number of single or doublet $\beta$ cells per section of pancreas examined.

Plasma analysis. Blood samples were obtained from the tail vein collected into heparinized capillary tubes and plasma separated by spinning in a microcentrifuge for 10 minutes at $4^{\circ} \mathrm{C}$. Glucose was measured on whole blood using an Hemocue glucose meter (Hemocue Inc., Mission Viejo, California, USA). Plasma insulin levels were determined on $5-\mu l$ aliquots by using a rat insulin ELISA kit with a mouse insulin standard (Crystal Chemical, Chicago, Illinois, USA).

Insulin secretion and glucose tolerance test. Following a 6hour fast, baseline blood glucose levels were measured in samples taken from the tail vein. Glucose $(2 \mathrm{mg} / \mathrm{g}$ body weight) in sterile PBS was injected intraperitoneally and blood glucose measured 30, 60, and 120 minutes after the injection. For measurement of insulin secretion, mice were starved and injected with glucose as described for the glucose tolerance test. Blood samples were collected at 5 and 15 minutes after the glucose injection.

Insulin secretion from isolated islets. Islet isolation was accomplished by collagenase digestion and differential centrifugation through Ficoll gradients using a modification of procedures described previously for rat islets (15). After overnight culture in RPMI containing $5 \mathrm{mM}$ glucose, islets of similar size from RIPAkt and wild-type mice were handpicked and precultured for an hour in Krebs-Ringer medium containing $2 \mathrm{mM}$ glucose. Groups of five islets in triplicate were incubated in Krebs-Ringer medium containing either $2 \mathrm{mM}$ glucose, $20 \mathrm{mM}$ glucose, or $30 \mathrm{mM} \mathrm{KCl}$, and incubated at $37^{\circ} \mathrm{C}$. After 1-hour incubation, culture medium was collected, stored at $-20^{\circ} \mathrm{C}$, and insulin measured by RIA.

Resistance to streptozotocin diabetes. RIP-Akt transgenic mice and their normal littermates were injected intraperitoneally in citrate buffer solution (Sigma Chemical Co., St Louis, Missouri, USA). The initial injection consisted of two doses of $75 \mathrm{mg} / \mathrm{kg}$ of streptozotocin (STZ: Sigma Chemical Co.) separated by 12 hours. Tail blood glucose was measured at baseline and after STZ injections at the indicated times. Progressive increase in the dose of STZ $(100 \mathrm{mg} / \mathrm{kg}$ and 200 $\mathrm{mg} / \mathrm{kg}$ ) at the times indicated in Figure 8 was required to induce hyperglycemia.

Statistical analysis. All values are expressed as mean plus or minus SEM. Statistical analysis was carried out using the Student $t$ test. Differences were considered statistically significant when $P$ values were less than 0.05 .

\section{Table 1}

Morphometric analysis of pancreas

\begin{tabular}{|c|c|c|c|c|}
\hline & \multicolumn{2}{|c|}{15 Days } & \multicolumn{2}{|c|}{5 Weeks } \\
\hline & $\begin{array}{l}\text { WT } \\
(n=4)\end{array}$ & $\begin{array}{l}\text { RIP-Akt } \\
(n=5)\end{array}$ & $\begin{array}{l}\text { WT } \\
(n=4)\end{array}$ & $\begin{array}{l}\text { RIP-Akt } \\
(n=5)\end{array}$ \\
\hline Islet area/pancreas area (\%) & $1.6 \pm 0.5$ & $12.7 \pm 3.9^{\mathrm{A}}$ & $0.6 \pm 0.1$ & $3.5 \pm 0.1^{\mathrm{B}}$ \\
\hline$\beta$ cell mass $(\mathrm{mg})$ & ND & ND & $118+23$ & $674 \pm 39^{B}$ \\
\hline $\begin{array}{l}\beta \text { cell number/pancreas area } \\
\left(\text { nuclei/ } \mu \mathrm{m}^{2}\right)\end{array}$ & $2 \pm 0.6$ & $6.9 \pm 1.7^{\mathrm{A}}$ & $0.4 \pm 0.04$ & $1.6 \pm 0.3^{\mathrm{A}}$ \\
\hline Cell size $\left(\mu \mathrm{m}^{2}\right)$ & $8,438 \pm 1,594$ & $17,582 \pm 1,885^{A}$ & $10,041 \pm 1,243$ & $21,521 \pm 2,487^{\mathrm{A}}$ \\
\hline BrdU incorporation (\%) & $1.1 \pm 0.5$ & $1.1 \pm 0.16$ & $0.6 \pm 0.2$ & $1.36 \pm 0.4^{\mathrm{A}}$ \\
\hline Single and doublet extra-islet $\beta$ cells & $11.4 \pm 2.6$ & $70.1 \pm 6^{B}$ & ND & ND \\
\hline
\end{tabular}




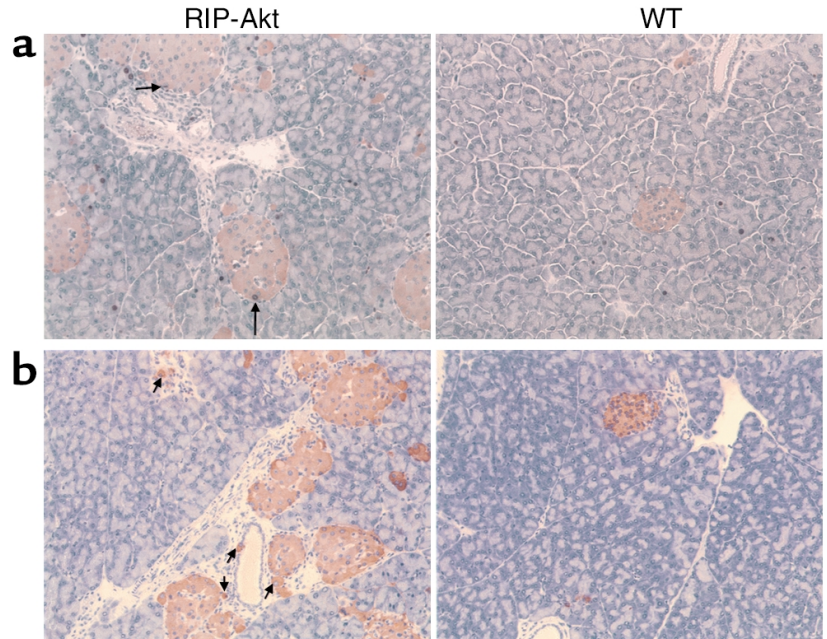

Figure 4

Assessment of proliferation and neogenesis in a pancreas from RIPAkt mice. (a) $\beta$ cell replication was demonstrated by BrdU incorporation (arrows) in cells stained for insulin (red) from transgenic (left) and control mouse (right). (b) Transgenic mice (left) showing evidence of neogenesis by $\beta$ cells budding from ductal cells (arrow), as well as increased single and doublet $\beta$ cells.

\section{Results}

Expression of Akt-1 in pancreatic islet $\beta$ cells of transgenic mice. The constitutively active Akt-1 lacks the $\mathrm{PH}$ domain (Akt $\Delta 4-129)$ and contains a Src myristoylation signal (myrAkt $\Delta 4$-129) along with an HA tag for monitoring expression (11). This sequence was inserted downstream of the rat insulin I promoter (RIP-Akt). After the transgene microinjection into mouse embryos, three founder mice were obtained. Progeny from all three lines were viable and fertile. Two lines were used for experiments, because the third line did not yield sufficient progeny. Two lines with similar phenotypes were observed, although the data presented below were obtained from line number 138. Transgene incorporation was demonstrated by Southern blot analysis in each of the lines (data not shown). Expression of the transgene was demonstrated by immunofluorescence using the anti$\mathrm{HA}$ tag Ab (Figure 1). No signal was observed in islets from the control mice (data not shown).

Expression of RIP-Akt in $\beta$ cells resulted in gross macroscopic and microscopic morphological changes. The size of pancreatic islets from 5-month-old RIP-Akt mice were so noticeably increased that many could be seen during dissections as variously sized white dots scattered throughout the pancreas (Figure 2). Histologic analysis confirmed that these grossly observed structures were islets, made visible by hematoxylin and eosin staining of pancreatic sections (Figure $3 a$ ). The islets appeared to be increased in size and number. Immunostaining for insulin in 5-week-old animals demonstrated that these large islet masses were mainly composed of $\beta$ cells (Figure 3b). An increase in $\beta$ cell mass was observed as early as 15 days (data not shown), and this increase appeared to be progressive when comparing the islet histology in mice between 5 weeks and 24 weeks of age (See Figure 3, a, 24 weeks, and $b, 5$ weeks). Islet non- $\beta$ cells were identified by immunostaining with a mixture of anti-glucagon, anti-pancreatic polypeptide, and anti-somatostatin Ab's. In contrast to islets from control mice that showed normal distribution of non- $\beta$ cells at the periphery, those from transgenic animals had non- $\beta$ cells that appeared to be randomly distributed throughout the islet core (Figure 3c). Another noteworthy phenotypic difference was the presence of cells coexpressing insulin and other islet hormones (Figure $3 c$, yellow-stained cells noted by arrows).

Estimation of the effects of RIP-Akt expression on the mass, number, size, and rates of proliferation of $\beta$ cells. Quantitative morphometric analysis was performed to estimate the magnitude of the increase in $\beta$ cell mass. As seen in Table 1 , an eight- to ninefold increase $(P<0.04)$ was evident as early as 15 days, calculated as the $\beta$ cell area/pancreas area. The evaluation in 5-week-old mice showed that both the $\beta$ cell area/pancreas area, as well as the islet $\beta$ cell mass (corrected by pancreatic weight), were elevated sixfold $(P<0.001)$. These findings indicated that overexpression of constitutively active Akt1 results in remarkable increase in $\beta$ cell mass and that these changes are evident as early as 15 days.

Histologic examination of insulin-stained sections suggested that the increase in $\beta$ cell mass could be accounted for by an increase in the number of $\beta$ cells in RIP-Akt mice. To determine the representative number of $\beta$ cells, nuclei from insulin-positive cells were counted and expressed as number per pancreatic area examined. As shown in Table 1 , the number of $\beta$ cells was increased by three- to fourfold both at 15 days $(P<0.04)$ and at 5 weeks $(P<0.04)$. The results of these studies indicated that the development of increased $\beta$
RIP-Akt

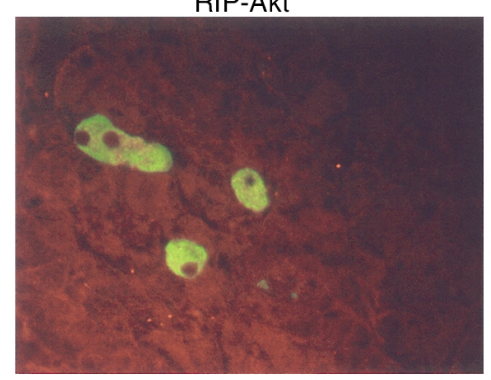

WT

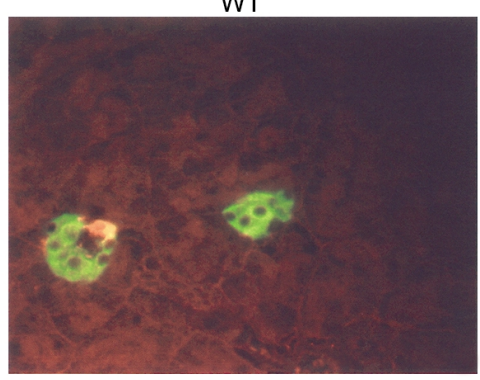

\section{Figure 5}

Alterations in pancreatic $\beta$ cell size observed in RIP-Akt mice. Immunofluorescence for insulin (green) in pancreatic sections (same magnification) from transgenic (left) and control mouse (right). This section illustrates the increased $\beta$ cell size in transgenic compared with WT mice. 
Table 2

Serum parameters

\begin{tabular}{lcccc}
\hline & \multicolumn{2}{c}{ Fed } & \multicolumn{2}{c}{ Fasting } \\
& WT & RIP-Akt & WT & RIP-Akt \\
& $(n=18)$ & $(n=10)$ & $(n=18)$ & $(n=10)$ \\
Glucose $(\mathrm{mg} / \mathrm{dl})$ & $166 \pm 5$ & $149 \pm 14$ & $147 \pm 7$ & $138 \pm 10$ \\
Insulin $(\mathrm{pg} / \mathrm{ml})$ & $1,313 \pm 107^{\mathrm{A}}$ & $2,270 \pm 188$ & $638 \pm 71^{\mathrm{A}}$ & $1,632 \pm 271$ \\
Cholesterol $(\mathrm{mg} / \mathrm{dl})$ & $66 \pm 2.4$ & $64 \pm 2.3$ & $71 \pm 3$ & $65 \pm 3$ \\
Triglycerides $(\mathrm{mg} / \mathrm{dl})$ & $64 \pm 5$ & $75 \pm 9$ & $54 \pm 3$ & $48 \pm 10$ \\
FFA $(\mathrm{mmol} / \mathrm{L})$ & $1.3 \pm 0.07$ & $1.4 \pm 0.15$ & $1.2 \pm 0.05$ & $1.2 \pm 0.08$ \\
\hline AP $<<0.01$ & & & &
\end{tabular}

samples from RIP-Akt and wild-type littermates were analyzed both in the fasting as well as the fed state. As shown in Table 2, RIP-Akt and wild-type littermates had similar blood glucose in the fasting and fed state. However, RIP-Akt mice exhibit 1.7-fold $(P<0.01)$ increase in plasma insulin levels in the fed state. The increase in plasma insulin (2.5-fold, $P<0.001)$ was also observed in the fasting state, suggesting the presence of insulin resistance. To determine whether the hyperinsulinemia found in RIP-Akt mice cell mass in transgenic mice could be accounted for at least in part by an increase in $\beta$ cell number.

Increase in $\beta$ cell number can result from increase in proliferation and/or decrease in apoptosis. To determine the proliferation rate in pancreatic islet $\beta$ cells in vivo, we performed BrdU incorporation into $\beta$ cell nuclei of RIPAkt mice and their normal littermates. An example of BrdU- and insulin-positive cells is shown in Figure 4a. The percentage of insulin-positive cells also positive for BrdU incorporation was not different in 15-day-old animals (Table 1), while $\beta$-cell replication was estimated to be increased twofold $(P<0.04)$ in RIP-Akt compared with wild-type mice at 5 weeks of age (Table 1 ). These results indicate that an increase in $\beta$ cell replication was at least one of the mechanisms contributing to the increase in $\beta$ cell number and thus mass in RIP-Akt mice.

The observed increased islet $\beta$ cell number could be the result of enhanced neogenesis, as well as replication. Quantitation of neogenesis has been difficult to achieve because there are neither markers for new $\beta$ cells nor time denominators for the process (16). However, a current definition of neogenesis includes $\beta$ cells budding from the ducts or scattered as single or doublet cells within the exocrine pancreas (15). By these criteria, numerous insulin-positive cells budding from ductal epithelium were noted in transgenic mice (see Figure $4 \mathrm{~b}$, for example) compared with wild-type mice, although this was not quantitated. A significant increase in extra islet single and doublet insulin-positive cells was observed in transgenic animals (Table 1 , $P<0.001$ ), see for example Figures 3, a-c.

Examination of pancreatic sections suggested that in addition to increased $\beta$ cell number, the islet mass was also increased because the size of both the nuclei and cytoplasm of the RIP-Akt mice appeared larger than in wild-type littermates (see for example Figure 5). To estimate the contribution of $\beta$ cell size to the increase in mass, the $\beta$ cell area was divided by the number of $\beta$ cell nuclei in the covered area (Table 1 ). Islet $\beta$ cell size was increased twofold $(P<0.04)$ in RIP-Akt compared with wild-type mice both at 15 days and at 5 weeks, respectively. These results indicate that the increase in islet $\beta$ cell mass in RIP-Akt mice could be accounted for by increases in both cell size and number.

Assessment of metabolic abnormalities in RIP-Akt mice. To determine whether the increase in $\beta$ cell mass induces abnormalities in glucose or lipid metabolism, blood resulted in alterations in lipid metabolism, blood samples were analyzed for cholesterol, triglycerides, and free fatty acid (FFA) levels. Similar levels for cholesterol, triglycerides, and FFA were observed in both groups (Table 2).

RIP-Akt mice exhibit improved glucose tolerance and hyperinsulinemia. To define the impact of the morphological changes in RIP-Akt mice on glucose homeostasis, glucose tolerance tests were performed. In the fasting state, blood glucose concentrations were similar in RIP-Akt mice and wild-type littermates (Figure 6a). After glucose injection, transgenic mice had significantly lower blood glucose levels at 30 and 60 minutes. The blood glucose levels returned to the same levels as in the fasted state in both groups at 120 minutes. These results suggest that the RIP-Akt mice have an increased ability to dispose of the injected glucose. To determine whether these differences were associated with alterations in insulin secretory function, glucose-stimulated insulin secretion was evaluated next. The insulin levels in the fasting state were threefold higher $(P<0.001)$ in the RIP-Akt mice compared with wild-type littermates (Figure 6b). Acute insulin release in response to glucose as measured at 5 minutes was conserved in the RIP-Akt mice (Figure 6b). The results of these experiments indicate that RIP-Akt mice have increased basal insulin levels and conserved insulin secretion to a glucose challenge.

Insulin secretion is conserved in RIP-Akt islets. To assess whether RIP-Akt mice have alterations in glucose-stimulated insulin secretion in vitro, static incubation of
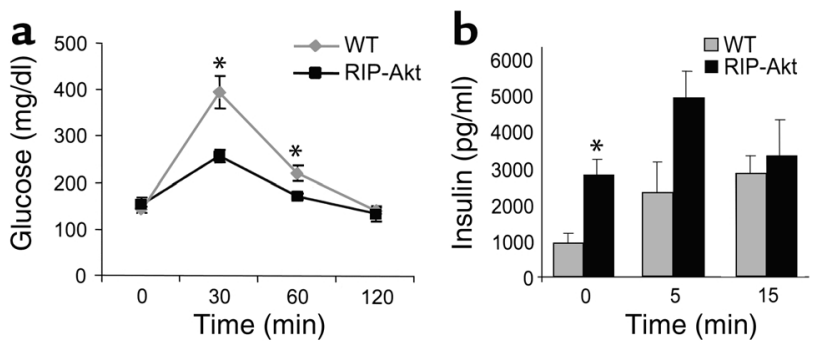

Intraperitoneal glucose tolerance tests. Five-month-old mice were fasted 6 hours, then injected with glucose $(2 \mathrm{mg} / \mathrm{g}$ body weight). Blood samples from the tail vein were obtained at the indicated times. Plasma glucose (a) (RIP-Akt, $n=4$, and WT, $n=5$ ) and insulin (b) (RIP-Akt, $n=3$, and WT, $n=3$ ). Results are presented as mean \pm SEM. ${ }^{*} P<0.01$.

\section{Figure 6}




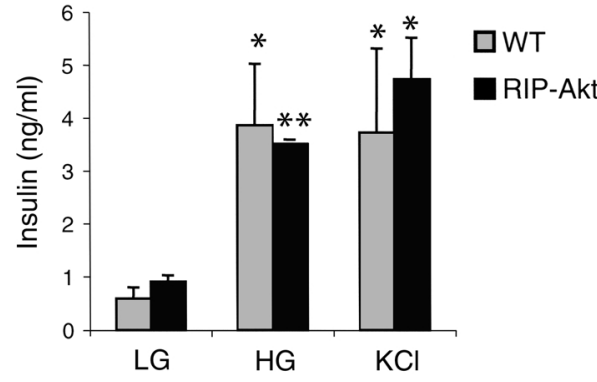

Figure 7

Assessment of insulin secretion in isolated islets. Incubation of islets in the presence of $2 \mathrm{mM}$ glucose (LG), $20 \mathrm{mM}$ glucose (HG), and 30 $\mathrm{mM} \mathrm{KCl}$ was performed as described in Methods. Islets were isolated from 2- to 3-month-old RIP-Akt $(n=4)$ and WT littermates $(n=3)$. Results are mean \pm SEM. ${ }^{*} P<0.05 ;{ }^{*} P<0.01$.

isolated islets of similar size was performed. Isolated islets from RIP-Akt mice had a 3.5- and a fourfold increase $(P<0.05$ and $P<0.01$, respectively) in insulin secretion after stimulation with glucose and $\mathrm{KCl}$ (Figure 7). Glucose- and $\mathrm{KCl}$-induced insulin secretion in islets from wild-type mice were not significantly different from that obtained from the RIP-Akt mice (Figure 7). The results of these experiments suggest that islets from RIP-Akt mice are functional and support the results obtained from the intraperitoneal glucose tolerance and insulin secretion in vivo.

RIP-Akt mice exbibit resistance to STZ-induced diabetes. To determine whether overexpression of Akt in pancreatic $\beta$ cells resulted in decreased susceptibility to experimental diabetes, RIP-Akt and normal littermates were injected intraperitoneally with STZ. As shown in Figure 8 , all the wild-type animals $(n=13)$ developed diabetes after three injections of STZ at the indicated doses. In contrast, the blood glucose levels in RIP-Akt mice were unchanged after STZ injections, suggesting that these mice are resistant to STZ-induced diabetes.

\section{Discussion}

To determine the role of Akt in pancreatic islet $\beta$ cells we have overexpressed this enzyme by creating transgenic animals using the insulin promoter coupled to the amino-terminal myristoylation sequence of c-Src fused to the coding sequence of Akt-1 lacking the PH domain. While there was no overall effect on body growth, the RIP-Akt transgenic animals displayed a remarkable expansion of islet mass. Others have noted that transgenic mice with targeted expression of certain islet growth factors (17-20) exhibit up to threefold expansion of islet $\beta$ cell mass. In the current study the RIP-Akt transgenic mice were noted to have an islet mass six to eight times that of wild-type controls in response to overexpression of a single endogenous $\beta$ cell protein, a kinase incriminated in the mitogen-activated PI3K-signaling pathway in other cells. The insulin-signaling PI3K pathway has been shown to be involved in the regulation of islet $\beta$ cell mass as demonstrated by targeted disruptions of the insulin receptor and insulin receptor substrates-1 and -2 (21). The current observations strongly suggest that in islet $\beta$ cells in vivo, Akt- 1 may be an important component of this pathway.

Islet $\beta$ cell mass is coordinately regulated by changes in cell size, replication, neogenesis, and cell death (16). Little is known about the role of the PI3K/Akt pathway in controlling cell size in mammals (22). In Drosophila, insulin signaling through the IRS- 1 homologue (CHICO) has been shown to be a critical regulator of cell size (23). Further, Drosophila Akt (Dakt1) has also been shown to be involved in cell size regulation (24). Transgenic mice expressing a constitutively active p110 subunit of PI3K in cardiac myocytes developed cardiac hypertrophy predominantly through an increase in cell size (25). A downstream target of activated Akt is the ribosomal S6 kinase S6K1 ( $\mathrm{p} 70^{S 6 K}$ ), a kinase involved in regulation of cell growth. Both glucose and IGF1-stimulated proliferation of INS-1 mouse insulinoma cells were shown to be associated with activation of S6K1 (10). Recently, S6K1-deficient mice were shown to have hypoinsulinemia, glucose intolerance, and decreased islet cell mass with a selective reduction in $\beta$ cell size (26). In Drosophila S6K1 deficiency is also associated with a severe reduction in body size along with smaller and fewer cells (27). These findings suggest that S6K1 may be a critical downstream target of activated Akt- 1 responsible for regulation of $\beta$ cell mass, and this hypothesis can now be tested. Our findings of increased $\beta$ cell size in transgenic mice overexpressing a constitutively active Akt 1 are consistent with the role of the conserved PI3K-Akt pathway for control of cell size. Other potential targets of activated Akt-1 that could be responsible, at least in part, for the observed phenotype include GSK-3 (28) and members of the Forkhead family of transcription factors (29).

The observed expansion of islet $\beta$ cell number in the Akt transgenic mice may perhaps be the result of both increased replication and neogenesis. It is known that glucose stimulation of $\beta$ cell proliferation in cultured islets was due to enhancement of the number of cells

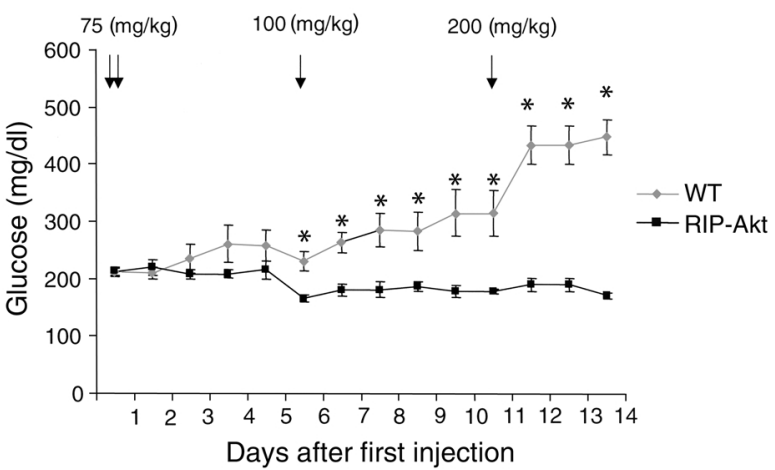

\section{Figure 8}

Effect of STZ administration on blood glucose levels in RIP-Akt and control. Two- to three-month-old RIP-Akt $(n=5)$ and WT $(n=12)$ mice were subjected to intraperitoneal injections. STZ injections (arrows) were performed at the indicated doses. Results are expressed as mean \pm SEM. ${ }^{*} P<0.01$. 
entering the cell cycle, rather than a shortening of S/G2 phases (5). Recently, it has been shown that a key regulatory step in progression of cells from G0/G1 to the cell cycle is the activation of cyclin dependent kinases (Cdk's) (30). Interestingly, loss of Cdk-4 in mice resulted in insulin-dependent diabetes, while activation of Cdk-4 produced $\beta$-cell hyperplasia (31). Akt has been shown in other cells to alter proliferation by regulating $\mathrm{Cdk} /$ cyclin complexes through GSK-3 and by regulation of the Cdk inhibitors $\mathrm{p} 21^{\text {WAF1 }}$ and $\mathrm{p} 27^{\mathrm{kip} 1}$ (7). The results of these and the current study suggest that the adaptive hyperplastic responses of $\beta$ cells associated with chronic hyperglycemia might be explained by activation of Akt and cyclin/Cdk pathways.

It should be noted that at day 15 the islet area was increased sixfold, the $\beta$ cell number was increased threefold, and the $\beta$ cell size estimated at a twofold increase, while the BrdU was not different between transgenics and wild-type mice. What could explain the large increase in $\beta$ cell mass when proliferation does not appear to be different? Certainly, increased cell size accounts for some of the increase in mass. But what accounts for the increase in cell number? There are several possible explanations for these observations: (a) BrdU incorporation measures proliferation only during the 6 hours it is incorporated and may therefore lead to overestimation of the rates in the wild-type mice; (b) rates of proliferation may be high at day 15 , a period in which apoptosis is reported to be at its highest (evidence that proliferation is high in wild-type mice was seen in the decrease in BrdU incorporation between day 15 and 5 weeks), thus high rates of BrdU incorporation in wild-type mice might not be distinguished from that in transgenics at this time; and (c) finally, the increased cell number at day 15 could be solely accounted for by increased survival, i.e., decreased apoptosis in the RIPAkt mice. Unfortunately, apoptosis rates are low and difficult to measure given the evanescent nature of the phenomenon in vivo, and the possible contribution of decreased apoptosis to the increased cell number has not been assessed.

The effects of activated Akt on cell survival for neuronal and other tissues have been noted (9). While inhibition of apoptosis, in addition to the observed increase in proliferation, may contribute to the increased $\beta$ cell mass in RIP-Akt mice, we were unable to assess this parameter. The resistance to developing diabetes demonstrated after multiple doses of STZ can be partially explained by augmented survival in the RIP-Akt islets, since islet $\beta$ cells subjected to STZ have been shown to undergo apoptosis $(32,33)$. Measurements of apoptosis at various times of development will be necessary to fully assess the contribution of enhanced cell survival to the observed phenotype in RIP-Akt mice.

In the fasted and fed state the plasma glucose did not differ between transgenic and control mice, while the plasma insulin levels were 1.7 and 3 times higher, respectively, in the RIP-Akt mice (Table 2 and Figure $6 \mathrm{~b})$. The increase in plasma insulin in the fasted state is likely the result of the combined effects of increase in $\beta$ cell mass along with insulin resistance, an adaptive response to chronic hyperinsulinemia (21). Furthermore, the conservation of the insulin secretory response to a glucose challenge and the static incubation of isolated islets from RIP-Akt mice suggested that overexpression of Akt under these conditions resulted in expansion of normal functioning islet $\beta$ cells rather than tumor formation. Whereas Akt can act as an oncogene in certain tissues, we have not observed insulinomas in any of the RIP-Akt mice.

The responses to multiple doses of STZ demonstrate a remarkable resistance of RIP-Akt mice to developing experimental diabetes. The mechanisms involved in STZ induction of diabetes are poorly understood and involve direct cytotoxic activity, autoimmune responses, or a combination. It is believed that high doses of STZ $(200 \mathrm{mg} / \mathrm{kg})$ cause a direct cytotoxic effect on $\beta$ cells, perhaps through the formation of alkylating compounds from STZ metabolism (34). In addition to an increase in susceptibility to apoptosis, the different response of RIP-Akt mice to high-dose STZ could be explained as: (a) the transgenic pancreas is able to rapidly replenish $\beta$ cell mass by neogenesis or replication, or (b) the increase in $\beta$ cell mass makes this animal resistant to the doses used to induce diabetes in normal mice. The resistance to developing diabetes in RIP-Akt mice can now be tested in vivo by crossbreeding with animal models with intrinsic predisposition to $\beta$ cell failure.

In summary, the current observations establish that activation of the Akt $1 / \mathrm{PKB} \alpha$ pathway in islet $\beta$ cells in vivo has major effects on their size, number, and function. This identifies Akt as a kinase-controlling pathway that could be altered in disease states such as type 1 and/or type 2 diabetes. Because this pathway appears to be regulated by both nutrients and growth factors, it can now serve to provide candidates for genetic analysis of the failure of $\beta$ cells to respond to the insulin resistance of diabetes. Furthermore, this observation may provide new targets for therapeutic intervention and for expansion of human islet $\beta$ cells for transplantation.

\section{Acknowledgments}

We gratefully acknowledge Hiroshi Inoue, Burton Wice, and Carlos Bernal-Mizrachi for their careful comments and suggestions. We also acknowledge Michael Shornick, Matteo Levisetti, Burton Wice, and Tray Coleman's assistance with immunostaining techniques and technical support. The authors would like to thank Gary Skolnick for preparation of the manuscript. This work was supported in part by NIH grant DK-16746 (M.A. Permutt) and the Diabetes Research and Training Center for technical support.

Note added in proof. A similar phenotype was recently described by Tuttle et al. in a transgenic mouse overexpressing the same Akt construct under the control of the rat insulin promoter II. (Tuttle, R.L., et al. 2001. 
Regulation of pancreatic beta-cell growth and survival by the serine/threonine protein kinase Akt1/PKBalpha. Nat Med. 7:1133-1137.)

1. Bruning, J.C., Winnay, J., Cheatham, B., and Kahn, C.R. 1997. Differential signaling by insulin receptor substrate 1 (IRS-1) and IRS-2 in IRS-1deficient cells. Mol. Cell. Biol. 17:1513-1521.

2. Steil, G.M., et al. 2001. Adaptation of beta-cell mass to substrate oversupply: enhanced function with normal gene expression. Am. J. Physiol. Endocrinol. Metab. 280:E788-E796.

3. Finegood, D.T., Scaglia, L., and Bonner-Weir, S. 1995. Dynamics of betacell mass in the growing rat pancreas. Estimation with a simple mathematical model. Diabetes. 44:249-256.

4. Garcia-Ocana, A., et al. 2001. Hot topic-using beta-cell growth factors to enhance human pancreatic islet transplantation. J. Clin. Endocrinol. Metab. 86:984-988.

5. Swenne, I. 1982. The role of glucose in the in vitro regulation of cell cycle kinetics and proliferation of fetal pancreatic B-cells. Diabetes. 31:754-760.

6. Hugl, S.R., White, M.F., and Rhodes, C.J. 1998. Insulin-like growth factor I (IGF-I)-stimulated pancreatic beta-cell growth is glucose-dependent. Synergistic activation of insulin receptor substrate-mediated signal transduction pathways by glucose and IGF-I in INS-1 cells. J. Biol. Chem. 273:17771-17779.

7. Kandel, E.S., and Hay, N. 1999. The regulation and activities of the multifunctional serine/threonine kinase Akt/PKB. Exp. Cell Res. 253:210-229.

8. Toker, A. 2000. Protein kinases as mediators of phosphoinositide 3 kinase signaling. Mol. Pharmacol. 57:652-658.

9. Datta, S.R., Brunet, A., and Greenberg, M.E. 1999. Cellular survival: a play in three Akts. Genes Devel. 13:2905-2927.

10. Dickson, L.M., et al. 2001. Differential activation of protein kinase B and p70(S6K) by glucose and insulin-like growth factor 1 in pancreatic betacells (INS-1). J. Biol. Chem. 276:21110-21120.

11. Kohn, A.D., Takeuchi, F., and Roth, R.A. 1996. Akt, a pleckstrin homology domain containing kinase, is activated primarily by phosphorylation. J. Biol. Chem. 271:21920-21926.

12. Dandoy-Dron, F., Itier, J.M., Monthioux, E., Bucchini, D., and Jami, J. 1995. Tissue-specific expression of the rat insulin 1 gene in vivo requires both the enhancer and promoter regions. Differentiation. 58:291-295.

13. Dandoy-Dron, F., Monthioux, E., Jami, J., and Bucchini, D. 1991. Regulatory regions of rat insulin I gene necessary for expression in transgenic mice. Nucleic Acids Res. 19:4925-4930.

14. Hogan, B., Costantini, F., and Lacy, E. 1986. Manipulating the mouse embryo: a laboratory manual. Cold Spring Harbor Laboratory Press. Plainview, New York, USA. 157 pp.

15. Lacy, P.E., and Kostianousky, M. 1967. Method for the isolation of intact islets of Langerhans from the rat pancreas. Diabetes. 16:35-39.
16. Bonner-Weir, S. 2000. Life and death of the pancreatic beta cells. TEM. 11:375-378.

17. Devedjian, J.C., et al. 2000. Transgenic mice overexpressing insulin-like growth factor-II in beta cells develop type 2 diabetes. J. Clin. Invest. 105:731-740

18. Porter, S.E., et al. 1998. Progressive pancreatic islet hyperplasia in the islet-targeted, parathyroid hormone-related protein-overexpressing mouse. Endocrinology. 139:3743-3751.

19. Garcia-Ocana, A., et al. 2000. Hepatocyte growth factor overexpression in the islet of transgenic mice increases beta cell proliferation, enhances islet mass, and induces mild hypoglycemia. J. Biol. Chem. 275:1226-1232.

20. Vasavada, R.C., et al. 2000. Targeted expression of placental lactogen in the beta cells of transgenic mice results in beta cell proliferation, islet mass augmentation, and hypoglycemia. J. Biol. Chem. 275:15399-15406.

21. Kido, Y., et al. 2000. Tissue-specific insulin resistance in mice with mutations in the insulin receptor, IRS-1, and IRS-2.J. Clin. Invest. 105:199-205.

22. Conlon, I., and Raff, M. 1999. Size control in animal development. Cell. 96:235-244.

23. Bohni, R., et al. 1999. Autonomous control of cell and organ size by CHICO, a Drosophila homolog of vertebrate IRS1-4. Cell. 97:865-875.

24. Verdu, J., Buratovich, M.A., Wilder, E.L., and Birnbaum, M.J. 1999. Cellautonomous regulation of cell and organ growth in Drosophila by Akt/PKB. Nat. Cell Biol. 1:500-506.

25. Shioi, T., et al. 2000. The conserved phosphoinositide 3-kinase pathway determines heart size in mice. EMBO J. 19:2537-2548

26. Pende, M., et al. 2000. Hypoinsulinaemia, glucose intolerance and diminished beta-cell size in S6K1-deficient mice. Nature. 408:994-997.

27. Montagne, J., et al. 1999. Drosophila S6 kinase: a regulator of cell size. Science. 285:2126-2129.

28. Ferkey, D.M., and Kimelman, D. 2000. GSK-3: new thoughts on an old enzyme. Dev. Biol. 225:471-479.

29. Kops, G.J., and Burgering, B.M. 1999. Forkhead transcription factors: new insights into protein kinase B (c-akt) signaling. J. Mol. Med. 77:656-665.

30. Jones, S.M., and Kazlauskas, A. 2001. Growth factor-dependent signaling and cell cycle progression. FEBS Lett. 490:110-116.

31. Rane, S.G., et al. 1999. Loss of Cdk4 expression causes insulin-deficient diabetes and Cdk4 activation results in beta-islet cell hyperplasia. Nat Genet. 22:44-52.

32. O’Brien, B.A., Harmon, B.V., Cameron, D.P., and Allan, D.J. 1996. Betacell apoptosis is responsible for the development of IDDM in the multiple low-dose streptozotocin model. J. Pathol. 178:176-181.

33. Cardinal, J.W., et al. 2001. Increased susceptibility to streptozotocininduced beta-cell apoptosis and delayed autoimmune diabetes in alkylpurine-DNA-N-glycosylase-deficient mice. Mol. Cell. Biol. 21:5605-5613.

34. Wilson, G.L., and Leiter, E.H. 1990. Streptozotocin interactions with pancreatic beta cells and the induction of insulin-dependent diabetes. Curr. Top. Microbiol. Immunol. 156:27-54. 